\title{
Comparison of Cytosolic and Mitochondrial Enzyme Alterations in the Livers of Propionic or Methylmalonic Acidemia: A Reduction of Cytochrome Oxidase Activity
}

\author{
Kiyoshi Hayasaka, Kikuya Metoki, Tsuruo Satoh, \\ Kuniaki Narisawa, Keiya Tada, Tadashi Kawakami,* \\ Nobutake Matsuo $\dagger$ and Tsugutoshi Aoki ${ }_{+}^{+}$ \\ Department of Pediatrics, Tohoku University School of \\ Medicine Sendai 980, *Department of Neonatology, Japan Red \\ Cross Hospital Center, Tokyo 150, †Department of Pediatrics, \\ Tokyo Metropolitan Kiyose Children's Hospital, Tokyo 180-04 \\ and †Department of Pediatrics, Toho University School of \\ Medicine, Tokyo 143
}

Hayasaka, K., Metoki, K., Satoh, T., Narisawa, K., Tada, K., Kawakami, T., Matsuo, N. and Aoki, T. Comparison of Cytosolic and Mitochondrial Enzyme Alterations in the Livers of Propionic or Methylmalonic Acidemia: A Reduction of Cytochrome Oxidase Activity. Tohoku J. exp. Med., 1982, 137 (3), 329-334 — The activities of mitochondrial, cytosolic and microsomal enzymes in liver specimens obtained from three patients with propionic or methylmalonic acidemia were compared with those of control patients who had died from unrelated causes. Only the activity of cytochrome oxidase (mitochondrial enzyme) was significantly reduced in the patients of propionic acidemia and methylmalonic acidemia who were in the state of metabolic acidosis; in two patients the activity was less than $30 \%$ of that in controls, but in the other patient of propionic acidemia, who was under the treatment with a low protein diet $(0.8 \mathrm{~g} / \mathrm{kg} / \mathrm{day})$, the activity was $50 \%$ of that in controls. The metabolites of branched chain amino acids (tiglic acid, propionic acid, methylmalonic acid, succinic acid, tiglyl-CoA and propionyl CoA) exhibited no inhibitory effect on the cytochrome oxidase activity of the sonicated rat liver mitochondria. The reduction of cytochrome oxidase activity found in these organic acidemias may be caused secondarily by some unknown mechanism. - propionic acidemia; methylmalonic acidemia; cytochrome oxidase

Propionic and methylmalonic acidemias are rare inborn errors of metabolism. These disorders are often accompanied by hyperammonemia, lactic acidosis and fatty degeneration of the liver (Tanaka 1975; Rosenberg 1978), similar to those of Reye's syndrome. There is ample evidence that mitochondrial enzyme activities in the liver are reduced in Reye's syndrome (Snodgrass and DeLong 1976; Mitchell et al. 1980). In addition to these similarities to Reye's syndrome, the

Received for publication, December 2, 1981 .

A part of the present findings have been published in preliminary form [Hayasaka et al. 1981]. 
activity of the glycine cleavage system in the liver mitochondria is siginficantly reduced in propionic or methylmalonic acidemia (Yoshida et al. 1969; Tada et al. 1974; Hayasaka et al. 1982). To examine in more detail the function of hepatic mitochondria in propionic or methylmalonic acidemia, the activities of cytosolic and mitochondrial enzymes in the livers of the patients were compared with those in control subjects.

\section{Materials and Methods}

\section{Chemicals}

Cytochrome c, $\mathrm{NAD}^{+}$, propionyl $\mathrm{CoA}$ and tiglyl $\mathrm{CoA}$ were obtained from Sigma Chemical Company, St. Louis, MO. Reduced cytochrome c was prepared by reduction with ascorbic acid (Wharton and Tzagoloff 1967).

\section{Patients}

Patient K.H. (propionic acidemia) became progressively ill, showing muscular hypotonia and convulsions since age of 12 days. She had hyperglycinemia and hyperammonemia and died in the state of metabolic acidosis at the age of 53 days. After her death, a diagnosis of propionic acidemia was made by a marked excretion of propionic acid in urine and a deficiency of propionyl CoA carboxylase activity in the liver (Hayasaka et al. 1982).

Patient C.A. (propionic acidemia) suffered from frequent episodes of vomiting and lethargy associated with acidosis soon after birth. She had hyperglycinemia and hyperammonemia. Since the $65 \mathrm{th}$ day of age, she was put on a low protein diet $(0.8 \mathrm{~g} / \mathrm{kg} /$ day), and her clinical symptoms improved with the decrease of blood ammonia and plasma glycine. On the 118th day of age, the liver specimens were biopsied for enzymatic diagnosis. Then the defect of propionyl CoA carboxylase was demonstrated. Details were described in our previous report (Hayasaka et al. 1982).

Patient S.H. (methylmalonic acidemia) had methylmalonic acidemia and deficiency of methylmalonyl CoA mutase activity in leukocytes. She was well controlled by dietary therapy until 10 months of age, as described in our previous report (Satoh et al. 1981; Hayasaka et al. 1982). Since 20 months of age, she could not be controlled and died at 21 months in the state of metabolic acidosis.

\section{Preparation of liver homogenates}

The liver specimens of the patients were obtained at the time of autopsy, frozen and stored at $-80^{\circ} \mathrm{C}$ within $4 \mathrm{hr}$ after death.

For control studies, samples of livers were obtained at autopsy from 5-month-old female and 3-year-old male who died of congenital heart disease, from 53-year-old male who died of lung tumor, from 8-year-old female who died of sudden cardiac arrest of unknown cause, and from 48-year-old male who died of cerebral hemorrhage. All specimens of controls were frozen within $2-6 \mathrm{hr}$ after death. Informed consent was obtained from the families of all subjects for this study.

Frozen tissues were thawed and homogenized with 9 volumes of $0.25 \mathrm{M}$ sucrose containing $5 \mathrm{mM}$ Tris-HCl buffer $(\mathrm{pH}$ 7.4). After centrifugation $(600 \times \mathrm{g}$ for $10 \mathrm{~min})$, the supernatant was used for enzyme assays.

\section{Preparation of rat liver mitochondria}

Wistar rats weighing 150-200 g were killed by decapitation, and the liver mitochondria were prepared according to the method of Schneider and Hogeboom (1950). Mitochondria were suspended in $0.25 \mathrm{M}$ sucrose containing $5 \mathrm{mM}$ Tris-HCl buffer $(\mathrm{pH} 7.4)$ and were subjected to sonic disintegration at $140 \mathrm{~W}$ for $5 \mathrm{~min}$. 


\section{Assay of enzyme activities}

The following enzymes were assayed by measuring the change in absorbance at $340 \mathrm{~nm}$ using a spectrophotometer: lactate dehydrogenase (EC. 1.1.1.27) (Schwartz and Bodansky 1966), alanine aminotransferase (EC. 2.6.1.2) (Segal and Matsuzawa 1970), glucose 6phosphate dehydrogenase (EC. 1.1.1.49) (Langdon 1966), glutamate dehydrogenase (EC 1.4.1.3) (Beaufay et al. 1959) and NADP+-linked isocitrate dehydrogenase (EC. 1.1.1.42) (assay conditions, Sigma Technical Bulletin No. 153, March, 1977). The activity of aspartate aminotransferase (EC. 2.6.1.1) was determined by the rate of oxaloacetate formation according to the method of Bergmeyer and Bernt (1974). The activity of gluccse 6 phosphatase (EC. 3.1.3.9) was measured by the rate of $\mathrm{Pi}$ formation according to the method of Nordlie and Arion (1966). Determination of monoamine oxidase (EC. 1.4.3.4) activity was performed by measuring increases in absorbance at $250 \mathrm{~nm}$ according to the method of Tabor et al. (1955). The activity of succinate dehydrogenase (EC. 1.3.99.1) was measured by the method of Prospero (1974). The assay of cytochrome oxidase (EC. 1.9.3.1) activity was determined by the rate of cyanide sensitive oxidation of reduced cytochrome c essentially according to the method of Wharton and Tzagoloff (1967).

\section{Protein determination}

This was done by the method of Lowry et al. (1951).

\section{Results}

The activities of ten enzymes in the liver specimens obtained from the patients with propionic or methylmalonic acidemia were compared with those of control cases (Table 1). Only the activity of cytochrome oxidase located in the inner mitochondrial membrane was remarkably reduced in Patient K.H. (propionic acidemia)

TABLE 1. Enzyme activities in the liver from propionic acidemia, methylmalonic acidemia or control cases ${ }^{1}$

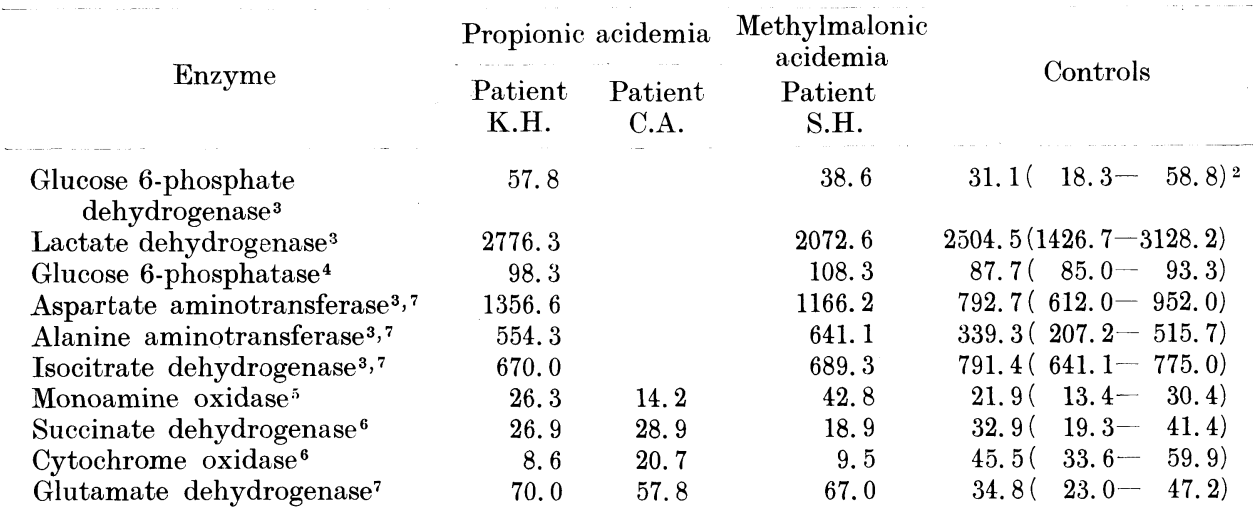

1) Enzyme activities are expressed as nmoles of product per min per $\mathrm{mg}$ protein except for monoamine oxidase for which the activity was expressed in terms of units per $\mathrm{mg}$ protein (one unit of enzyme is defined as the amount of enzyme which produces an initial rate of change in optical density at $250 \mathrm{~nm} 0.001$ per min at $30^{\circ} \mathrm{C}$ ).

2) Mean and range are obtained from five control cases.

3) Cytosol.

4) Endoplasmic reticulum.

5) Outer mitochondrial membrane.

6) Inner mitochondrial membrane.

7) Mitochondrial matrix. 
and Patient S.H. (methylmalonic acidemia); it was less than $30 \%$ of that in controls. On the other hand, the reduction of cytochrome oxidase activity in Patient C.A. (propionic acidemia) was not so remarkable in the liver, which was obtained at biopsy under the treatment with a low protein diet $(0.8 \mathrm{~g} / \mathrm{kg} / \mathrm{day})$; it was $50 \%$ of that in controls. The lower activity of cytochrome oxidase in the patients did not appear to be due to the presence of an inhibitor in the livers of the patients based on the results of the mixed experiments (data not shown). None of the activities of other mitochondrial, cytosolic and microsomal enzymes in the livers of the patients described in Table 1 was reduced as compared with those in controls; some were rather elevated, especially those of glucose 6-phosphatase, aspartate aminotransferase, alanine aminotransferase and glutamate dehydrogenase.

A number of metabolities of branched-chain amino acids were tested for their effects on cytochrome oxidase in the sonicated mitochondria of the rat liver. As shown in Table 2, no compound tested exhibited inhibitory effect on the cytochrome oxidase activity.

\section{Discussion}

The present study revealed that the activity of cytochrome oxidase in the liver was significantly reduced in patients with propionic or methylmalonic acidemia, especially in the patients with metabolic acidosis, such as Patients K.H. and S.H. We demonstrated in the previous report (Hayasaka et al. 1982) that the glycine cleavage activity in the liver was reduced in Patients K.H. and S.H., but the activity was not reduced in Patient C.A. So, the observed reduction of cytochrome oxidase seems to have occurred also secondarily. Gregersen (1979) and Stumpf et al. (1980) reported that propionate and other short chain carboxylic acids inhibited oxygen consumption by rat liver mitochondria when $\alpha$-ketoglutarate, pyruvate or succinate was substrate. In addition, Cathelineau et al. (1979) demonstrated that propionate acted to decrease the ATP content of rat liver mitochondria when succinate or glutamate was used as oxidizable substrate. These

TABLE 2. Effects of metabolites of branched-chain amino acids on the activity of cytochrome oxidase in the rat liver mitochondria

\begin{tabular}{lcr}
\multicolumn{1}{c}{ Additions } & $\begin{array}{c}\text { Activity } \\
\text { (nmoles/min/mg protein) }\end{array}$ & \% of control \\
\hline None & 1649.7 & 100 \\
Propionic acid & 1488.2 & 90 \\
Methylmalonic acid & 1649.7 & 100 \\
Tiglic acid & 1523.3 & 92 \\
Succinic acid & 1488.2 & 90 \\
Propionyl CoA & 1682.7 & 102 \\
Tiglyl CoA & 1699.2 & 103
\end{tabular}

All additions were $10 \mathrm{mM}$ except for propionyl $\mathrm{CoA}$ and tiglyl CoA that were $5 \mathrm{mM}$.

Mitochondria were prepared and used after sonic disintegration. Other conditions were described under Materials and Methods. 
observations suggest the possibility that propionate and other short chain carboxylic acids may cause a reduction of cytochrome oxidase activity, resulting in the decrease of oxygen consumption and ATP content in the mitochondria. However, the cytochrome oxidase activity was not reduced when rat liver mitochondria were incubated at $37^{\circ} \mathrm{C}$ for $10 \mathrm{~min}$ with $10 \mathrm{mM}$ propionate, methylmalonate or tiglic acid (data not shown). Furthermore, propionate, methylmalonate, tiglic acid, succinic acid, propionyl CoA or tiglyl CoA exhibited no inhibitory effect on the cytochrome oxidase activity of the sonicated rat liver mitochondria (Table 2). On the other hand, the decrease of cytochrome oxidase activity was not observed in the livers of the patients who died in the state of the metabolic acidosis due to other causes; pyruvate dehydrogenase complex deficiency and Leigh's encephalomyelopathy (Willems et al. 1977). Thus, the reduction of the cytochrome oxidase activity, as same as the disturbance of glycine cleavage system, would represent a dysfunction characteristic of the liver of the patients with propionic or methylmalonic acidemia, although the mechanism of the observed reduction remains unsolved.

\section{References}

1) Beaufay, H., Bendall, D.S., Bandhuin, P. \& Deduve, C. (1959) Tissue fractionation studies: 12. Intracellular distribution of some dehydrogenases, alkaline deoxyribonuclease and iron in rat-liver tissue. Biochem. J., 73, 623-628.

2) Bergmeyer, H.U. \& Bernt, E. (1974) Colorimetric assay with 6-benzamido-4-methoxym-toluidine diazonium chloride. In: Methods of Enzymatic Analysis, vol. 2, edited by H.U. Bergmeyer, Academic Press, New York-London, pp. 742-745.

3) Cathelineau, L., Petit. F.P., Coude, F.X. \& Kamoun, P.P. (1979) Effect of propionate and pyruvate on citrulline synthesis and ATP content in rat liver mitochondria. Biochem. biophys. Res. Commun., 90, 327-332.

4) Gregersen, N. (1979) Studies on the effects of saturated short-chain monocarboxylic acids on the energy metabolism of rat liver mitochondria. Pediat. Res., 13, 1227-1230.

5) Hayasaka, K., Metoki, K., Satoh, T., Narisawa, K. \& Tada, K. (1981) Reduction of cytochrome oxidase activity in the livers of propionic and methylmalonic acidemias. Biochem. int., 3, 51-54.

6) Hayasaka, K., Narisawa, K., Satoh, T., Tateda, H., Metoki, K., Tada, K., Hiraga, K., Aoki, T., Kawakami, T., Akamatsu, T. and Matsuo, N. (1982) Glycine cleavage system in ketotic hyperglycinemia. A reduction of H-protein activity. Pediat. Res., 16, 5-7.

7) Langdon, R.G. (1966) Glucose 6-phosphate dehydrogenase from erythrocytes. In: Methods in Enzymology, vol. 9, Carbohydrate Metabolism, edited by W.A. Wood, Academic Press, New York-London, pp. 126-131.

8) Lowry, O.H., Rosenbrough, N.J., Farr, A.L. \& Randall, R.J. (1951) Protein measurement with the Folin phenol reagent. J. biol. Chem., 193, 265-275.

9) Mitchell, R.A., Ram, M.L., Arcinue, E.L. \& Chang, C.H. (1980) Comparison of cytosolic and mitochondrial hepatic enzyme alterations in Reye's syndrome. Pediat. Res., 14, 1216-1221.

10) Nordlie, R.C. \& Arion, W.J. (1966) Glucose 6-phosphatase. In: Methods in Enzymology, vol. 9, Carbohydrate Metabolism, edited by W.A. Wood, Academic Press, New York-London, pp. 619-625.

11) Prospero, T.D. (1974) Assay method of succinic dehydrogenase activity. In: Methodological Developments in Biochemistry, vol. 4, edited by E. Reid, Longman Press, London, p. 411.

12) Rosenberg, L.E. (1978) Disorders of propionate, methylmalonate, and cobalamine 
metabolism. In: The Metabolic Basis of Inherited Disease. 4th ed., edited by J.B. Stanbury, J.B. W yngaarden \& D.S. Frederickson, McGraw-Hill, New York, pp. 411-429.

13) Satoh, T., Narisawa, K., Igarashi, Y., Saitoh, T., Hayasaka, K., Ichinohazama, Y., Onodera, H., Tada, K. \& Oohara, K. (1981) Dietary therapy in two patients with vitamin $\mathrm{B}_{12}$-unresponsive methylmalonic acidemia. Europ. J. Pediatr., 135, 305312.

14) Schneider, W.C. \& Hogeboom, G.H. (1950) Intracellular distribution of enzymes V. Further studies on the distribution of cytochrome $\mathrm{c}$ in rat liver homogenates. $J$. biol. Chem., 183, 123-128.

15) Schwartz, M.K. \& Bodansky, O. (1966) Lactic dehydrogenase (clinical aspects). In: Methods in Enzymology, vol. 9, Carbohydrate Metabolism, edited by W.A. Wood, Academic Press, New York-London, pp. 294-302.

16) Segal, H.L. \& Matsuzawa, T. (1970) L-Alanine aminotransferase (rat liver). In: Methods in Enzymology, vol. 17 A, Metabolism of Amino Acids and Amines, edited by H. Tabor \& C.W. Tabor, Academic Press, New York-London, pp. 153-163.

17) Snodgrass, P.J. \& DeLong, G.R. (1976) Urea-cycle enzyme deficiencies and an increased nitrogen load producing hyperammonemia in Reye's syndrome. New Engl. J. Med. 294, 855-860.

18) Stumpf, D.A., McAfee, J., Parks, J.K. \& Eguren, L. (1980) Propionate inhibition of succinate CoA ligase (GDP) and the citric acid cycle in mitochondria. Pediat. Res., 14, 1127-1131.

19) Tabor, C.W., Tabor, H. \& Rosenthal, S.M. (1955) Amine oxidase from steer plasma. In: Methods in Enzymology, vol. 2, edited by S.P. Colowick \& N.O. Kaplan, Academic Press, New York-London, pp. 390-393.

20) Tada, K., Corbeel, L.M., Eeckels, R. \& Eggermont, E. (1974) A block in glycine cleavage reaction as a common mechanism in ketotic and nonketotic hyperglycinemia. Pediat. Res., 8, 721-723.

21) Tanaka, K. (1975) Disorders of organic acid metabolism. In: Biology of Brain Dysfunction, vol. 3, edited by G.E. Gaul, Plenum Publishing Corporation, New York, pp. 145-214.

22) Wharton, D.C. \& Tzagoloff, A. (1967) Cytochrome oxidase from beef heart mitochondria. In: Methods in Enzymology, vol. 10, Oxidation and Phosphorylation, edited by R.W. Estabrook \& M.E. Pullman, Academic Press, New York-London, pp. 245250.

23) Willems, J.L., Monnens, L.A.H., Trijbels, J.M.F., Veerkamp, J.H., Meyer, A.E.F.H., van Dam, K. \& van Haest, U. (1977) Leigh's Encephalomyelopathy in a patient with cytochrome c oxidase deficiency in muscle tissue. Pediatrics, 60, 850-857.

24) Yoshida, T., Kikuchi, G., Tada, K., Narisawa, K. \& Arakawa, T. (1969) Physiological significance of glycine cleavage system in human liver as revealed by the study of a case of hyperglycinemia. Biochem. biophys. Res. Commun., 35, 577-583. 